\title{
Pigment epithelium-derived factor inhibits angiogenesis and growth of gastric carcinoma by down-regulation of VEGF
}

\author{
YANG ZHANG $^{1,2^{*}}$, JIANDE HAN ${ }^{2 *}$, XIA YANG ${ }^{1,3}$, CHUNKUI SHAO $^{4}$, ZUMIN XU $^{1}$, RUI CHENG ${ }^{1}$, \\ WEIBIN CAI ${ }^{1}$, JIANXIN MA ${ }^{6}$, ZHONGHAN YANG $^{1}$ and GUOQUAN GAO ${ }^{1,5}$ \\ ${ }^{1}$ Department of Biochemistry, Zhongshan School of Medicine, Sun Yat-sen University; ${ }^{2}$ Department of Medicine, \\ First Affiliated Hospital of Sun Yat-sen University; ${ }^{3}$ Key Laboratory of Functional Molecules from Marine \\ Microorganisms, Sun Yat-sen University, Department of Education of Guangdong Province; ${ }^{4}$ Department \\ of Pathology, Third Affiliated Hospital of Sun Yat-sen University; ${ }^{5}$ China Key Laboratory of Tropical \\ Disease Control, Sun Yat-sen University, Ministry of Education, Guangzhou, P.R. China; ${ }^{6}$ Department \\ of Cell Biology, University of Oklahoma Health Sciences Center, Oklahoma City, OK 73104, USA
}

Received March 17, 2011; Accepted April 21, 2011

DOI: 10.3892/or.2011.1318

\begin{abstract}
Previous studies have shown that pigment epithelium-derived factor (PEDF) is an antitumor candidate with anti-oxidative, anti-inflammatory and anti-angiogenesis properties. However, the effect of PEDF on gastric carcinoma has not been elucidated. MTT assay and Annexin V/PI staining were performed. Immunohistochemistry was applied to detect microvessel density (MVD) of a xenograft model. The protein levels of vascular endothelial growth factor (VEGF) were examined by Western blot analysis and hypoxia-inducible factor- $1 \alpha$ (HIF-1 $\alpha$ ) translocation was investigated by immunofluorescence. Results showed that growth and angiogenesis of gastric carcinoma were suppressed after PEDF injection. PEDF could not directly suppress proliferation or induce apoptosis of gastric carcinoma cells. However, the expression of VEGF both in tumor tissues and gastric carcinoma cells was down-regulated by PEDF. The amount and nuclear translocation of HIF-1 $\alpha$, the transcription factor of VEGF, was also inhibited by PEDF. In conclusion, PEDF suppresses angiogenesis and growth of gastric carcinoma by down-regulating HIF-1 $\alpha$ and VEGF and may have potential for gastric carcinoma treatment.
\end{abstract}

Correspondence to: Dr Guoquan Gao, or Dr Zhonghan Yang, Department of Biochemistry, Zhongshan School of Medicine, Sun Yat-sen University, 74 Zhongshan 2 Road, Guangzhou 510080, P.R. China

E-mail: gaogq@mail.sysu.edu.cn

E-mail: yangzhh@mail.sysu.edu.cn

*Contributed equally

Key words: pigment epithelium-derived factor, gastric carcinoma, angiogenesis, vascular endothelial growth factor, hypoxia-inducible factor- $1 \alpha$

\section{Introduction}

Gastric carcinoma is a common malignancy, and the second cause of cancer-related deaths (1). There are about 800,000 annual deaths worldwide (2). The five-year survival rate for gastric carcinoma with distant metastasis is much lower than that for localized malignancies (3).

Angiogenesis, proliferating new vessels from pre-existing capillaries, has an important role in the metastasis and prognosis of gastric carcinoma (4). VEGF, secreted by tumor cells, is a main angiogenesis inducer, supporting tumor growth and enhancing metastasis (5). Therefore, anti-angiogenesis therapy may be a strategy in gastric carcinoma therapy.

Pigment epithelium-derived factor (PEDF), a 50-kDa glycoprotein present in most tissues of the body, is a member of the serpin family (6). It is a multifunctional molecule that binds to a cell membrane receptor, performing neuroprotective, neurotrophic, anti-oxidative and anti-inflammatory activities $(7,8)$. Additionally, PEDF is an active endogenous angiogenic inhibitor and tumor treatment candidate (9). Previous studies elucidated that PEDF may induce endothelial cell apoptosis and suppress tumor growth (10-13). However, whether PEDF could inhibit gastric carcinoma growth has not been investigated. In this study, the anti-tumor effect of PEDF was investigated in animal experiments, and the intrinsic mechanism was explored.

\section{Materials and methods}

Cell culture and reagents. Human gastric carcinoma SGC7901 cells were purchased from the Cell Bank of Sun Yat-sen University (Guangzhou, China) and maintained in RPMI-1640 medium (R1640) supplemented with 10\% (v/v) FBS (Gibco-BRL, Gaithersburg, MD) and incubated under normal conditions (at $37^{\circ} \mathrm{C}$ with $5 \% \mathrm{CO}_{2}$ ). Human umbilical vein endothelial cells (HUVECs), isolated from umbilical vein cords of normal pregnancies (14), were cultured in M199 medium (Gibco-BRL) with $15 \%$ FBS and endothelial cell growth supplement (ECGS) (BD Biosciences, CA), and cultured at $37^{\circ} \mathrm{C}$ with $5 \% \mathrm{CO}_{2}$. 
HUVECs at passages 2-6 were used in all the experiments. PEDF protein was acquired as previously described (15). Briefly the PEDF cDNA was inserted into the pET30a plasmid (Novagen). Soluble PEDF was purified using the His-Tag affinity method (Novagen) as recommended by the manufacturer. The recombinant PEDF was confirmed by Western blot analysis using a PEDF antibody produced as previously described (16).

Animal model. Suspensions $(0.1 \mathrm{ml})$ of SGC7901 cells $\left(5 \times 10^{7}\right.$ cells $/ \mathrm{ml}$ ) in R1640 were injected subcutaneously in the dorsal site of male athymic mice (BALB/c nu/nu, 18-22 g, Center of Experimental Animal, Sun Yat-sen University). When the volume of tumors reached $50 \mathrm{~mm}^{3}$, the mice were randomly separated into PEDF and PBS groups ( $n=5$ in each group). The PEDF group received an intraperitoneal injection of $5 \mathrm{mg} / \mathrm{kg}$ PEDF per mouse every other day. The overall dosage per mouse was $15 \mathrm{mg} / \mathrm{kg}$. The control group was treated with the same volume of PBS. The length and width of the tumors were measured every second day. The tumor volume was calculated by the equation: volume $=\left(\right.$ length $\mathrm{x}$ width $\left.{ }^{2}\right) / 2$. The tumors were excised four weeks after the first injection and weighed. The inhibition ratio of PEDF was calculated by the following equation: Inhibition ratio $(\%)=[(\mathrm{C}-\mathrm{T}) / \mathrm{C}] \times 100 \%$, where $\mathrm{C}$ and $\mathrm{T}$ are the average tumor weight of the PBS and PEDF group, respectively. All animal experiments were carried out according to the US Public Health Service Guide for the Care and Use of Laboratory Animals.

Cell proliferation assay. Cell viability was determined using the 3-(4,5-dimethylthiazol-2-yl-2,5-diphenyltetrazolium bromide (MTT) (Sigma Chemical Co., St. Louis, MO) assay. SGC7901 cells or HUVECs at a density of $2 \times 10^{4}$ cells/well were seeded into 24-well plates in triplicate. After adherence, the medium was changed to M199 with 2\% FBS for HUVECs or to serum-free R1640 for SGC7901 cells with various concentrations of PEDF (0, 40, 80, 160, 320 and $640 \mathrm{nmol} / \mathrm{l})$. After treatment for another $72 \mathrm{~h}, 100 \mu \mathrm{l}$ fresh medium with $5 \mathrm{mg} / \mathrm{ml} \mathrm{MTT} \mathrm{was} \mathrm{added} \mathrm{into} \mathrm{each} \mathrm{well} \mathrm{and} \mathrm{the} \mathrm{cells} \mathrm{were}$ cultured for another $4 \mathrm{~h}$. The medium was then aspirated and $1 \mathrm{ml}$ dimethyl sulfoxide (DMSO) (Sigma) was added into each well. The absorbance was measured at $570 \mathrm{~nm}$. Data are expressed as the percentage of viable cells compared to controls. The anti-proliferation effects of PEDF on the cells were determined from three independent tests.

Annexin V/PI analysis. About $1 \times 10^{5}$ cells per well were seeded into 6-well plates. Twenty hours later, cells were cultured for another $72 \mathrm{~h}$ with $320 \mathrm{nmol} / \mathrm{l}$ PEDF. Then the cells were trypsinized, washed twice with PBS, then resuspended in $1 \mathrm{X}$ binding buffer with $5 \mu \mathrm{l}$ Annexin $\mathrm{V}$ and $5 \mu \mathrm{l}$ propidium iodide (PI) from the Annexin V/PI kit (Keygen, China) following the protocol recommended by the manufacturer. The apoptosis ratio of the $25 \mu \mathrm{mol} / 1$ colchicine-treated group was used as a positive control. The apoptotic cells were subsequently counted by flow cytometry.

Western blot analysis. SGC7901 cells were cultured in 90-mm plates until $70 \%$ confluence. The cells were then incubated with serum-free medium containing different concentrations of PEDF (0, 40, 80, 160, 320 and $640 \mathrm{nmol} / \mathrm{l})$ under normoxia $\left(20 \% \mathrm{O}_{2}, \mathrm{v} / \mathrm{v}\right)$ or hypoxia $\left(1 \% \mathrm{O}_{2}, \mathrm{v} / \mathrm{v}\right)$ at $37^{\circ} \mathrm{C}$ for the indicated time. The cells were lysed and the protein concentrations of the samples were detected using the Bio-Rad protein assay kit (Bio-Rad, Hercules, CA). Western blot analysis was performed with $60 \mu \mathrm{g}$ of cell lysates as previously described (17). The primary antibodies used were anti-VEGF (1:2,000, Abcam, USA); anti-Fas (1:1,000, Santa Cruz Biotechnology, Santa Cruz, CA); anti-HIF-1 $\alpha$ (1:1,000) and anti-FasL (1:1,000, BD Biosciences). The $\beta$-actin antibody (1:10,000, Sigma) was used as a control and was probed on the same membrane after stripping.

Immunofluorescence. SGC7901 cells were cultured in 6-well plates with coverslips and incubated overnight at $37^{\circ} \mathrm{C}$. The medium was then changed into serum-free R1640 with or without PEDF (320 nmol/l) and the cells were incubated under normoxia $\left(20 \% \mathrm{O}_{2}, \mathrm{v} / \mathrm{v}\right)$ or hypoxia $\left(1 \% \mathrm{O}_{2}\right.$, v/v) for another $9 \mathrm{~h}$. After washing twice with PBS, the cells were fixed with 4\% paraformaldehyde (Sigma) buffered in PBS for $15 \mathrm{~min}$. The cells were then permeabilized with $0.1 \%$ Triton $\mathrm{X}-100$ (Sigma) in PBS for $15 \mathrm{~min}$, followed by blocking for $30 \mathrm{~min}$ with $3 \%$ FBS in PBS. The cells were then incubated with HIF-1 $\alpha$ (BD Biosciences) antibody (1:50 in 3\% FBS) overnight at $4^{\circ} \mathrm{C}$. After washing twice with PBS, the cells were incubated in the dark with Alexa Fluor 594 anti-mouse $\operatorname{IgG}(20 \mu \mathrm{g} / \mathrm{ml}$, Invitrogen, USA) for $1 \mathrm{~h}$ at room temperature. After rinsing with DAPI (Vector Laboratories, Burlingame, CA), the cells were then analyzed using fluorescent microscopy (Olympus, JAP) using the IPP software (Image Plus Pro 6.0, Bethesda, MD, USA).

Immunohistochemistry. Heterotopic tumors were fixed in formalin and embedded in paraffin. To detect microvessel formation, $5 \mu \mathrm{m}$ histological sections were prepared. After endogenous peroxidase was blocked, the sections were incubated with normal goat serum for $1 \mathrm{~h}$ at room temperature. Antibodies against CD34 (1:100, Abcam, UK), and VEGF (1:50) were used and incubated overnight at $4^{\circ} \mathrm{C}$. After washing twice in PBS, sections were covered with biotinylated secondary antibody for $20 \mathrm{~min}$ at room temperature, washed twice, and then incubated with HRP-labeled streptavidin for another $20 \mathrm{~min}$. Finally, the results were visualized by a peroxidase reaction with diaminobenzidine (DAB) and quantified by Weidner's method (18). The amount of VEGF was indicated by integral optical density (IOD) using IPP (Image Plus Pro).

Statistical analysis. All data were analyzed by the Student's t-test using the SPSS 13.0 software. The results are expressed as the mean $\pm \mathrm{SD}$. Statistical significance was set at $\mathrm{P}<0.05$.

\section{Results}

To evaluate the effect of PEDF on gastric carcinoma growth, a heterotopic tumor xenografted model was established. Since the 12th day after the first injection, the average tumor size was significantly suppressed by PEDF (Fig. 1A-C; $\mathrm{P}<0.05$, $n=5)$. The average tumor weight of the PEDF group was notably lower than that of the control group (Fig. 1C). The results demonstrate that PEDF can effectively suppress gastric carcinoma growth in vivo. 
$\mathbf{A}$

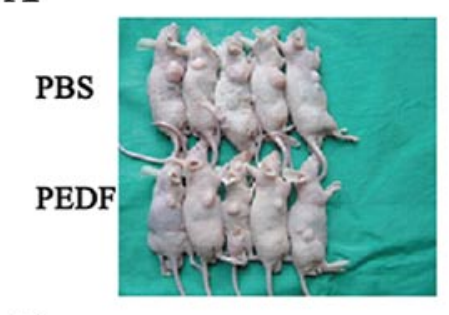

C

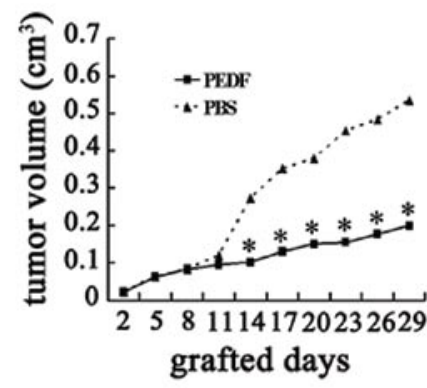

B

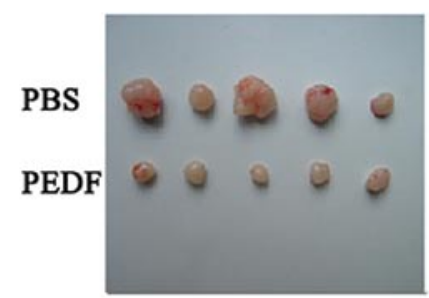

D

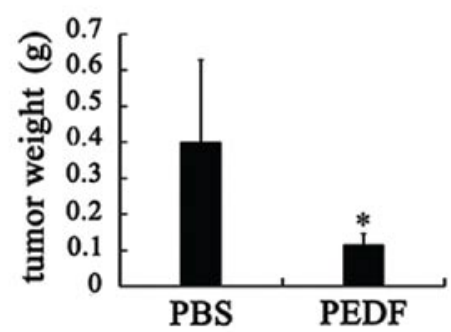

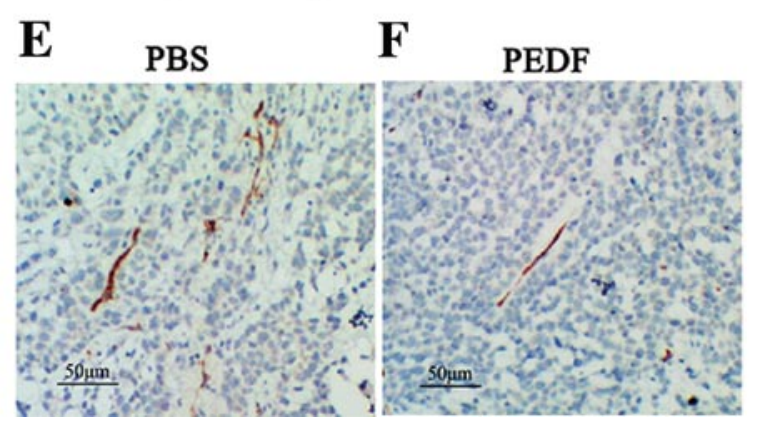

$\mathbf{G}$

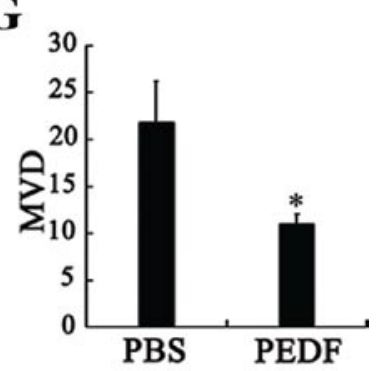

Figure 1. SGC7901 cell heterotopic transplanted tumors were developed as described in Materials and methods. Mice received an intraperitoneal injection of PEDF 7 days after transplantation. (A and B) Tumor growth was monitored, and tumor tissues were collected and weighed 4 weeks after the first injection of PEDF. (C) Tumor growth curves, volumes of PEDF- vs. PBS-treated group on days indicated. Data are presented as the mean \pm SD, $n=5$. Microvessel density (MVD) in tumor tissues were determined by immunohistochemical staining by an endothelial-specific antibody CD34. (D) Tumor weight at day 28 after treatment. An average of $71.1 \%$ suppression of primary tumor growth was observed. MVD of (E) PBS group and (F) PEDF group. (G) MVD quantitation. Data are presented as the mean $\pm \mathrm{SD}\left({ }^{*} \mathrm{P}<0.05\right)$.

To evaluate the effect of PEDF in tumor tissue, immunostaining of CD34, which exists in vascular endothelium and is a marker of angiogenesis, was performed. The amount of CD34-stained capillaries in the PEDF group was reduced compared with the PBS group (Fig. 1E and F). Microvessel density (MVD) of the PEDF group was markedly less than that of the PBS group (Fig. 1G, P<0.05). These results clearly demonstrate that PEDF could effectively inhibit neovascularization of gastric carcinoma in xenografted model.

Our previous report suggested that PEDF dose-dependently promotes apoptosis of HUVECs (17). The $\mathrm{IC}_{50}$ was $\sim 80 \mathrm{nmol} / 1$. However, in this study, as observed in the MTT assay, PEDF had no anti-proliferative effect on SGC7901 cells, even at a high concentration of $640 \mathrm{nmol} / \mathrm{l}$ (Fig. 2A). Annexin V-PI staining showed that the PEDF ( $320 \mathrm{nmol} / \mathrm{l})$ could not induce apoptosis of SGC7901 cells (Fig. 2B). Western blotting demonstrated that there is no difference in the protein levels of Fas and Fas-L between the PEDF and control groups, even after $72 \mathrm{~h}$ of treatment (Fig. 2C). Therefore, PEDF had no apparent inhibitory effect on SGC7901 cells.

Western blot analysis showed that PEDF (40-640 nmol/l) dose-dependently down-regulated the expression of VEGF after $24 \mathrm{~h}$ of treatment (Fig. 3A) under hypoxia. In xenografted tumor tissues, the VEGF level in the tumor tissue of the PEDF group was lower than that of the PBS group (Fig. 3B), which suggests that PEDF decreases the expression of VEGF in vivo. Therefore, VEGF expression could be down-regulated by PEDF both in vitro and in vivo.

HIF-1 $\alpha$ is the main regulator of VEGF expression. In order to elucidate the role of HIF-1 $\alpha$ in the PEDF-induced downregulation of VEGF expression, immunofluorescence and Western blotting were performed to analyze the localization and the amount, respectively, of HIF-1 $\alpha$ in SGC7901 cells after PEDF treatment. HIF-1 $\alpha$ protein levels were elevated prominently in hypoxic condition, and PEDF remarkably reduced HIF-1 $\alpha$ expression in SGC7901 cells (Fig. 4A). Immunofluorescence analysis showed that hypoxia significantly enhanced the stability and HIF-1 $\alpha$ nuclear translocation and PEDF notably decreased the translocation and expression of HIF-1 $\alpha$ under hypoxic conditions (Fig. 4B).

\section{Discussion}

Angiogenesis is essential for solid tumor growth and metastasis $(6,19)$. Anti-angiogenesis therapy provides a novel approach for cancer therapy (6). Angiogenesis provides a pathway for nutrient transportation and metastasis of gastric carcinoma. Studies have suggested that anti-angiogenic agents may be a 
A

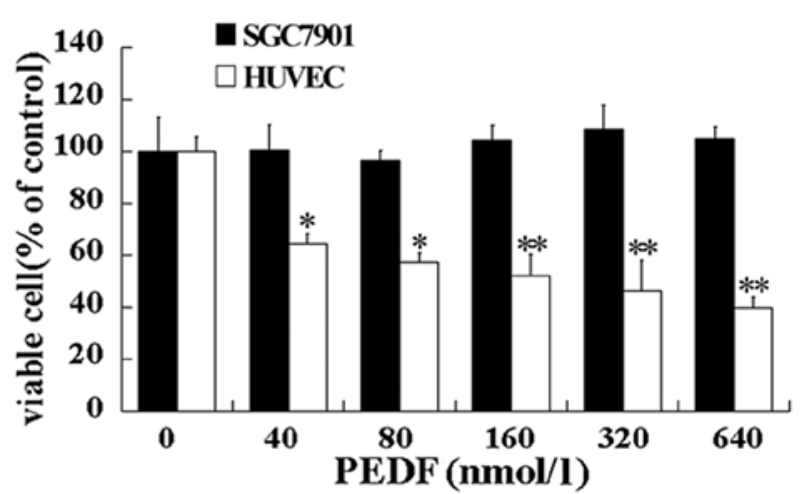

B
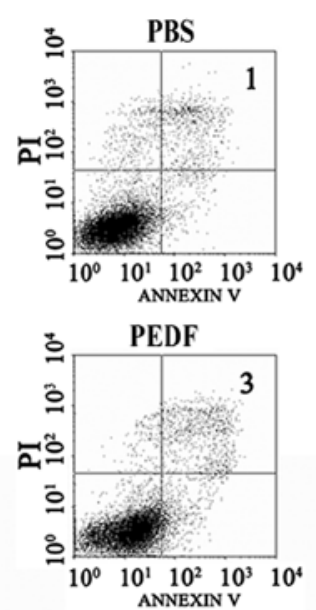
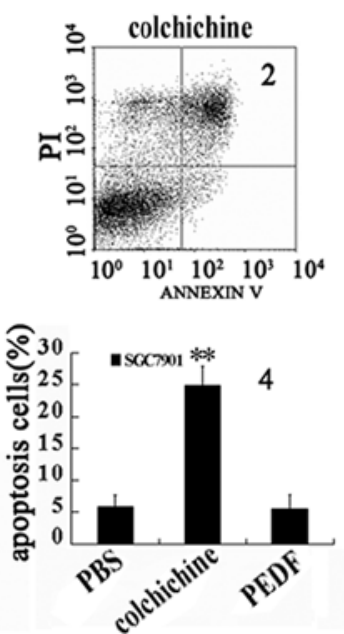

C

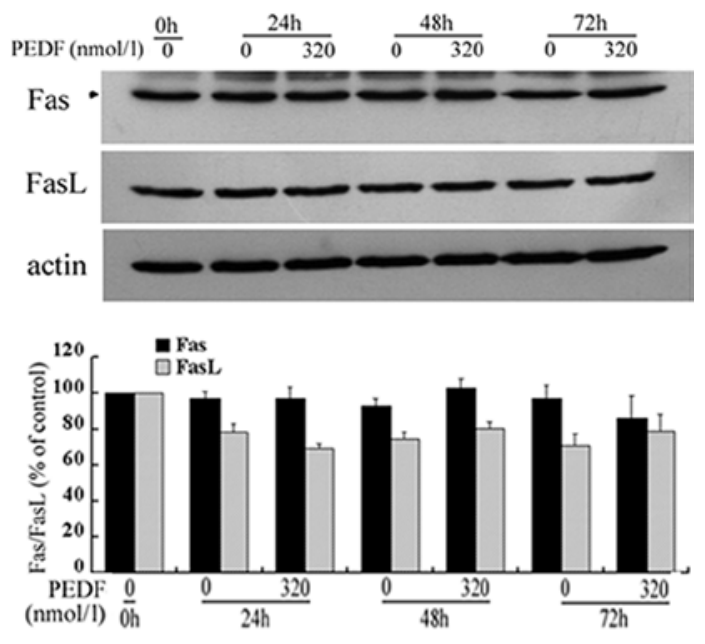

Figure 2. Primary HUVECs and SGC7901 cells were treated with PEDF at the indicated concentrations for $72 \mathrm{~h}$. (A) The viable cells were counted by the MTT assay (means \pm SD, n=3). (B) Quantitative analysis of SGC7901 cell apoptosis after treatment with PEDF for 72 h. Apoptotic cells were quantified by flow cytometric analysis. $1, \mathrm{PBS}$ as a negative control; 2, colchicine as a positive control; 3 , cells treated with PEDF at $320 \mathrm{nmol} / \mathrm{l}$; 4 , statistical analysis. (C) Fas and FasL were detected at different times after PEDF treatment. Values significantly higher than control are indicated $\left({ }^{*} \mathrm{P}<0.05,{ }^{* *} \mathrm{P}<0.01\right)$.

new method for gastric carcinoma treatment (20-22). This is the first research to elucidate that PEDF could inhibit gastric carcinoma growth in vivo. The MVD results showed that angiogenesis in tumor tissues was inhibited by PEDF (Fig. 1E and F). However, the MTT assay and apoptosis experiments performed on cell models suggested that PEDF had no effect on the proliferation and apoptosis of SGC7901 cells (Fig. 2) or another gastric carcinoma cell line, MGC 803 (data not shown), even at a high concentration of $640 \mathrm{nmol} / \mathrm{l}$ and after $72 \mathrm{~h}$ of treatment. The observation that PEDF could not induce gastric carcinoma cell apoptosis was further confirmed. Studies have shown that the Fas-FasL pathway may be involved in tumor apoptosis of human osteosarcoma and melanoma cells treated with PEDF (23). However, PEDF treatment did not alter the protein levels of Fas or Fas-L in the present study (Fig. 2C). These results suggest that the mechanism by which PEDF suppresses gastric carcinoma growth is mainly through blocking of angiogenesis instead through a directly pro-apoptotic effect on tumor cells. Y79 is a widely used human retinoblastoma cell line. Though the Fas-FasL signaling pathway was activated after PEDF treatment, the hypermethylation of caspase- 8 gene made this cell line resistant to apoptosis (24). On the other hand, in the hepatocellular carcinoma cell line HepG2, PEDF was reported to exert an anti-apoptotic effect via inhibition of Bcl-xL degradation in the lysosome (25). Collectively the data suggest that the effect of PEDF on tumor apoptosis is cell-type dependent, but the detailed mechanism remains to be elucidated.

VEGF is the most potent factor of pro-angiogenesis and is secreted by almost all types of tumor cells (26). In pathological neovascularization, angiogenesis stimulators such as VEGF, were up-regulated, while inhibitors, for example PEDF, were down-regulated (27). PEDF can restore this balance by restoring pro-angiogenic factor expression (28). VEGF is highly expressed in gastric carcinoma $(29,30)$. However, whether PEDF can balance VEGF protein levels in gastric carcinoma has not been investigated. We revealed that VEGF protein was significantly down-regulated both in SGC7901 cells and gastric carcinoma tissue treated with PEDF (Fig. 3).

HIF-1 $\alpha$ is a major transcription factor up-regulating VEGF expression $(31,32)$, and is significantly expressed in gastric carcinoma (30). Attenuation of HIF-1 $\alpha$ protein inhibited VEGF expression and suppressed tumor growth (33-35). We further examined if HIF-1 $\alpha$ was regulated by PEDF in SGC7901 cells 
A

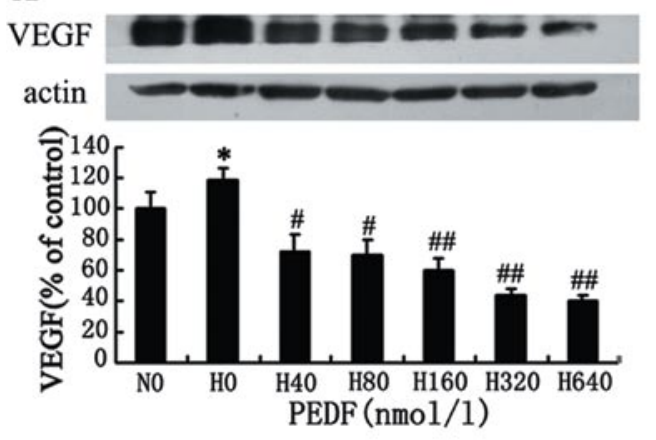

B
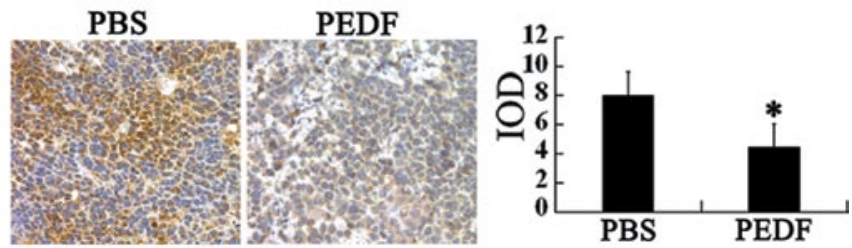

Figure 3. SGC7901 cells were treated with PEDF at the indicated concentrations for $24 \mathrm{~h}$ under normoxic or hypoxic conditions with $1 \%$ oxygen. (A) VEGF protein levels were measured by Western blot analysis and the results were normalized to $\beta$-actin. (B) The VEGF amount was investigated in heterotopic tumors by immunohistochemistry. " $\mathrm{P}<0.05$ compared with normoxia; ${ }^{\#} \mathrm{P}<0.05$ and ${ }^{\# \#} \mathrm{P}<0.01$ compared with hypoxia. IOD, integral optical density. and in xenograft tissue. HIF-1 $\alpha$ levels significantly increased under hypoxia compared to normoxia in the cell model. PEDF suppressed HIF-1 $\alpha$ protein levels and decreased its nuclear translocation (Fig. 4). These results suggest that PEDF inhibits VEGF expression via suppressing HIF-1 $\alpha$ protein.

In conclusion, the present study reported for the first time that PEDF suppresses gastric carcinoma growth by antiangiogenesis. PEDF may have potential for the treatment of gastric carcinoma.

\section{Acknowledgements}

This study was supported by the National Nature Science Foundation of China, Grant nos. 30570372, 30600724, 30672409, 30700120, 30872980, 30971208 and 30973449; the Team Project of the Nature Science Foundation of the Guangdong Province, China, Grant no. 06201946; the Key Sci-tech Research Project of the Guangdong Province, China, Grant no. 2008B080703027; the Key Sci-tech Research Project of the Guangzhou Municipality, China, Grant nos. 2007Z3-E5041, 2008Z1-E231 and 2009Z1-E201; the National Key Sci-Tech Special Project of China, Grant no. 2009ZX09103-642; the Program for Doctoral Station in University, Grant nos. 20070558209 and 20070558215; and the Key Sci-tech Research Project in University, Grant no. 108104.
A

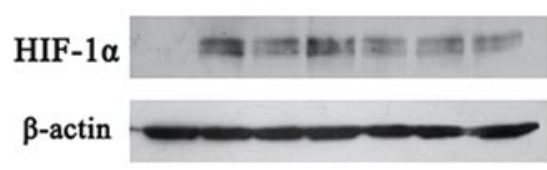

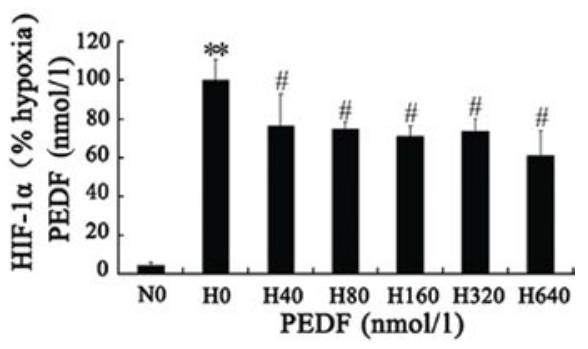

\section{B}

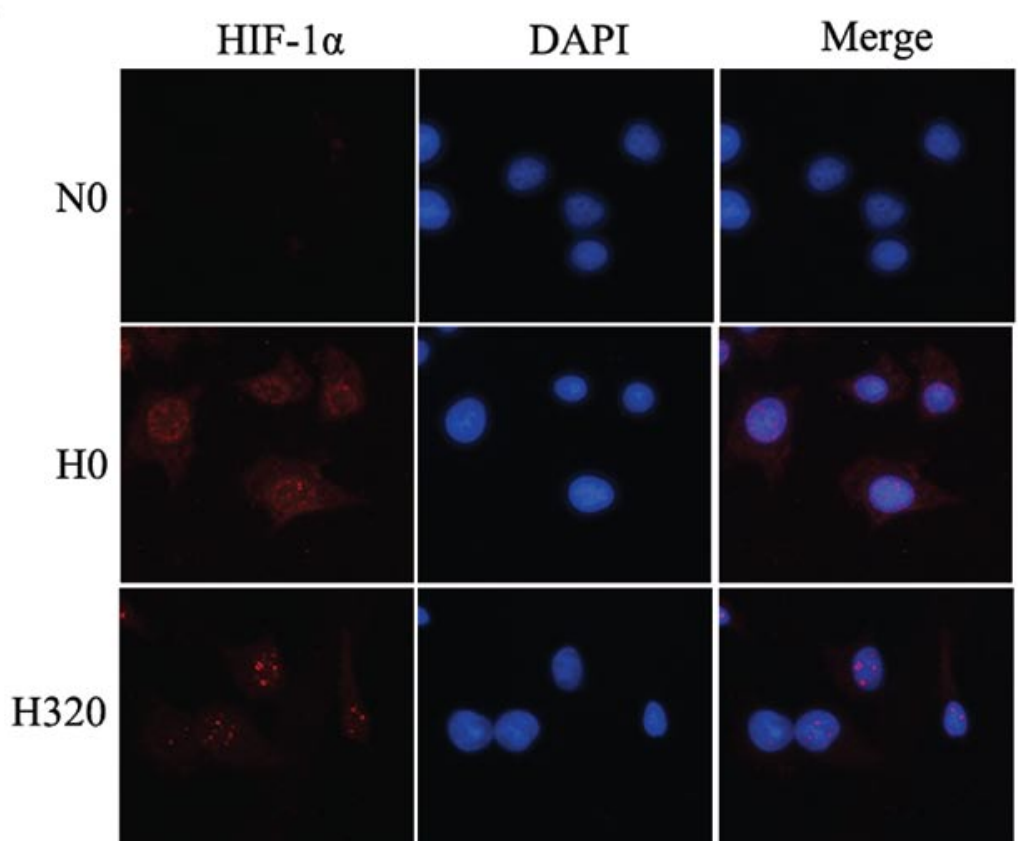

Figure 4. SGC7901 cells were treated with PEDF at the indicated concentrations for $9 \mathrm{~h}$ under normoxic or hypoxic conditions with $1 \%$ oxygen. The cells were then subjected to (A) immunoblotting or (B) immunofluorescence analysis. ${ }^{* *} \mathrm{P}<0.01$ compared with normoxia; ${ }^{\#} \mathrm{P}<0.05$ compared with hypoxia. 


\section{References}

1. Leung WK, Wu MS, Kakugawa Y, et al: Screening for gastric cancer in Asia: current evidence and practice. Lancet Oncol 9: 279-287, 2008

2. World Health Organization: Cancer. Fact sheet No. 297, February 2009. Available from www.who.int/mediacentre/factsheets/ fs297/en/ [Accessed January 30, 2011].

3. Catalano V, Labianca R, Beretta GD, Gatta G, de Braud F and Van Cutsem E: Gastric cancer. Crit Rev Oncol Hematol 54 209-241, 2005

4. Maehara Y, Kakeji Y, Oda S, Baba H and Sugimachi K: Tumor growth patterns and biological characteristics of early gastric carcinoma. Oncology 61: 102-112, 2001.

5. Carmeliet P: Angiogenesis in health and disease. Nat Med 9: 653-660, 2003

6. Dawson DW, Volpert OV, Gillis $\mathrm{P}$, et al: Pigment epitheliumderived factor: a potent inhibitor of angiogenesis. Science 285 245-248, 1999.

7. Filleur S, Volz K, Nelius T, et al: Two functional epitopes of pigment epithelium-derived factor block angiogenesis and induce differentiation in prostate cancer. Cancer Res 65: 5144-5152, 2005

8. Taniwaki T, Hirashima N, Becerra SP, Chader GJ Etcheberrigaray R and Schwartz JP: Pigment epithelium-derived factor protects cultured cerebellar granule cells against glutamate-induced neurotoxicity. J Neurochem 68: 26-32, 1997.

9. Abe R, Fujita Y, Yamagishi S and Shimizu H: Pigment epithelium-derived factor prevents melanoma growth via angiogenesis inhibition. Curr Pharm Des 14: 3802-3809, 2008.

10. Guan M, Pang CP, Yam HF, Cheung KF, Liu WW and Lu Y: Inhibition of glioma invasion by overexpression of pigment epithelium-derived factor. Cancer Gene Ther 11: 325-332, 2004.

11. Ho TC, Chen SL, Yang YC, Liao CL, Cheng HC and Tsao YP: PEDF induces p53-mediated apoptosis through PPAR gamma signaling in human umbilical vein endothelial cells. Cardiovasc Res 76: 213-223, 2007.

12. Abramson LP, Browne M, Stellmach V, et al: Pigment epithelium-derived factor targets endothelial and epithelial cells in Wilms' tumor. J Pediatr Surg 41: 1351-1356, 2006.

13. Chen L, Zhang SS, Barnstable CJ and Tombran-Tink J: PEDF induces apoptosis in human endothelial cells by activating p38 MAP kinase dependent cleavage of multiple caspases. Biochem Biophys Res Commun 348: 1288-1295, 2006.

14. Zhu B, Lu L, Cai W, et al: Kallikrein-binding protein inhibits growth of gastric carcinoma by reducing vascular endothelia growth factor production and angiogenesis. Mol Cancer Ther 6: 3297-3306, 2007.

15. Wang QS, Yang X, Yang ZH and Gao GQ: Novel method for expression and purification of human pigment epitheliumderived factor with biological activities in Escherichia coli. Prep Biochem Biotechnol 36: 127-138, 2006.

16. Gao G, Li Y, Zhang D, et al: Unbalanced expression of VEGF and PEDF in ischemia-induced retinal neovascularization. FEBS Lett 489: 270-276, 2001.

17. Yang H, Cheng R, Liu G, et al: PEDF inhibits growth of retinoblastoma by anti-angiogenic activity. Cancer Sci 100: 2419-2425 2009.
18. Garcia M, Fernandez-Garcia NI, Rivas V, et al: Inhibition of xenografted human melanoma growth and prevention of metastasis development by dual antiangiogenic/antitumor activities of pigment epithelium-derived factor. Cancer Res 64: 5632-5642, 2004.

19. Folkman J: Role of angiogenesis in tumor growth and metastasis. Semin Oncol 29: 15-18, 2002.

20. Zhang Q, Nie M, Sham J, et al: Effective gene-viral therapy for telomerase-positive cancers by selective replicative-competent adenovirus combining with endostatin gene. Cancer Res 64: 5390-5397, 2004.

21. Whisenant $\mathrm{J}$ and Bergsland E: Anti-angiogenic strategies in gastrointestinal malignancies. Curr Treat Options Oncol 6: 411-421, 2005.

22. Wei N, Fan JK, Gu JF, et al: Double-regulated oncolytic adenovirus-mediated interleukin-24 overexpression exhibits potent antitumor activity on gastric adenocarcinoma. Hum Gene Ther 21: 855-864, 2010.

23. Streck CJ, Zhang Y, Zhou J, Ng C, Nathwani AC and Davidoff AM: Adeno-associated virus vector-mediated delivery of pigment epithelium-derived factor restricts neuroblastoma angiogenesis and growth. J Pediatr Surg 40: 236-243, 2005.

24. Poulaki V, Mitsiades CS, McMullan C, et al: Human retinoblastoma cells are resistant to apoptosis induced by death receptors: role of caspase- 8 gene silencing. Invest Ophthalmol Vis Sci 46: 358-366, 2005.

25. Kawaguchi T, Yamagishi S, Itou M, et al: Pigment epitheliumderived factor inhibits lysosomal degradation of $\mathrm{Bcl}-\mathrm{xL}$ and apoptosis in HepG2 cells. Am J Pathol 176: 168-176, 2010.

26. Leung DW, Cachianes G, Kuang WJ, Goeddel DV and Ferrara N: Vascular endothelial growth factor is a secreted angiogenic mitogen. Science 246: 1306-1309, 1989.

27. Folkman J: Antiangiogenic gene therapy. Proc Natl Acad Sci USA 95: 9064-9066, 1998.

28. Stellmach V, Crawford SE, Zhou W, et al: Prevention of ischemiainduced retinopathy by the natural ocular antiangiogenic agent pigment epithelium-derived factor. Proc Natl Acad Sci USA 98: 2593-2597, 2001

29. Konno H, Ohta M, Baba M, Suzuki S and Nakamura S: The role of circulating IL-8 and VEGF protein in the progression of gastric cancer. Cancer Sci 94: 735-740, 2003.

30. Oh SY, Kwon HC, Kim SH, et al: Clinicopathologic significance of HIF-1alpha, p53, and VEGF expression and preoperative serum VEGF level in gastric cancer. BMC Cancer 8: 123, 2008.

31. Carmeliet P, Dor Y, Herbert JM, et al: Role of HIF-1alpha in hypoxia-mediated apoptosis, cell proliferation and tumour angiogenesis. Nature 394: 485-490, 1998.

32. Gerald D, Berra E, Frapart YM, et al: JunD reduces tumor angiogenesis by protecting cells from oxidative stress. Cell 118: 781-794, 2004.

33. Mizokami K, Kakeji Y, Oda S, et al: Clinicopathologic significance of hypoxia-inducible factor lalpha overexpression in gastric carcinomas. J Surg Oncol 94: 149-154, 2006.

34. Yeo EJ, Chun YS, Cho YS, et al: a potential anticancer drug targeting hypoxia-inducible factor 1 . J Natl Cancer Inst 95 516-525, 2003.

35. Stoeltzing O, McCarty MF, Wey JS, et al: Role of hypoxiainducible factor lalpha in gastric cancer cell growth, angiogenesis, and vessel maturation. J Natl Cancer Inst 96: 946-956, 2004. 